\title{
Weight Considerations in Pharmacotherapy for Type 2 Diabetes
}

\author{
Vicky Cheng and Sangeeta R. Kashyap \\ Department of Endocrinology, Diabetes, and Metabolism, Cleveland Clinic, 9500 Euclid Avenue, Cleveland, OH 44195, USA \\ Correspondence should be addressed to Sangeeta R. Kashyap, kashyas@ccf.org
}

Received 15 June 2010; Accepted 26 July 2010

Academic Editor: A. Halpern

Copyright ( 2011 V. Cheng and S. R. Kashyap. This is an open access article distributed under the Creative Commons Attribution License, which permits unrestricted use, distribution, and reproduction in any medium, provided the original work is properly cited.

\begin{abstract}
Obesity has been increasing in prevalence worldwide and the majority of patients with type 2 diabetes are either overweight or obese. Diabetes management in this population has been difficult since a number of antidiabetes agents are associated with weight gain. The effects of various antidiabetes agents and antiobesity agents on glycemic control and body weight will be reviewed. Briefly, sulfonylureas, thiazolidinediones, and insulin are associated with weight gain, whereas metformin and amylin analogs are weight neutral or associated with modest weight loss. Dipeptidyl-peptidase-4 inhibitors are weight neutral, whereas glucagon-like peptide- 1 analogs are associated with weight loss. The effect of orlistat and sibutramine in type 2 diabetes is also evaluated. The treatment of diabetes should not only focus on glycemic control as its sole intention, but it should factor in the effect of these various agents on weight, as well, since obesity aggravates insulin resistance, beta cell failure, and cardiovascular risk.
\end{abstract}

\section{Introduction}

Obesity has been increasing in prevalence worldwide and is strongly associated with the development of type 2 diabetes [1]. Both obesity and diabetes are associated with an increase in morbidity and mortality primarily from cardiovascular disease. Currently, about $86 \%$ of patients with type 2 diabetes are either overweight or obese [2]. Obesity, particularly intraabdominal obesity, induces insulin resistance in muscle and liver that leads to glucose intolerance [3]. Consequently, insulin resistance has long been targeted for diabetes control. Additionally, progressive loss of pancreatic beta cell function hallmarks the central defect in diabetes and is related to loss of incretin stimulation, amylin production, and the effects of glucotoxicity and lipotoxicity [4]. Hence, medical treatment of diabetes has collectively targeted these various pathophysiological mechanisms.

Intensive lifestyle modification with diet and exercise to achieve weight loss of at least $5-10 \%$ has been shown to improve glycemic control with improvements in insulin sensitivity and beta cell function [5]. Intensive glucose lowering of $\mathrm{HbAlc}$ levels to less than 7\% is associated with significant reduction in microvascular complications [6]. However, as has been shown in a number of prospective trials including the United Kingdom Prospective Diabetes
Study (UKPDS), intensive glucose control is associated with a median weight gain of $3-3.5 \mathrm{~kg}$. A more recent example of this effect is illustrated by the Action to Control Cardiovascular Risk in Diabetes (ACCORD) trial which compared standard therapy (HbA1c 7-7.9\%) with intensive glucose control $(<6 \%)$ in over 10,000 subjects [7]. More patients in the intensive group had significant weight gain of $>10 \mathrm{~kg}(28 \%$ versus $14 \%)$. For every $1 \%$ decrease in $\mathrm{HbAlc}$, there was a corresponding weight gain of about $2 \mathrm{~kg}$ [8]. Thus, the effect of antidiabetes agents on weight and obesity status is an important consideration when treating patients with diabetes since obesity, itself, aggravates insulin resistance and cardiovascular risk.

A number of medications including sulfonylureas, thiazolidinediones, and insulin are associated with weight gain particularly when used in combination, whereas metformin and amylin analogs are weight neutral or associated with modest weight loss. DPP4-inhibitors are weight neutral whereas GLP-1 analogs are associated with weight loss (Figure 1). The effect of various antidiabetes medication classes on glycemic control and weight will be reviewed here. Based on a practice-based approach, a therapeutic strategy that balances weight and glucose control for obese type 2 diabetic patients will be presented in Figure 2 that is distinct from the conventional glucose lowering approach [9]. 


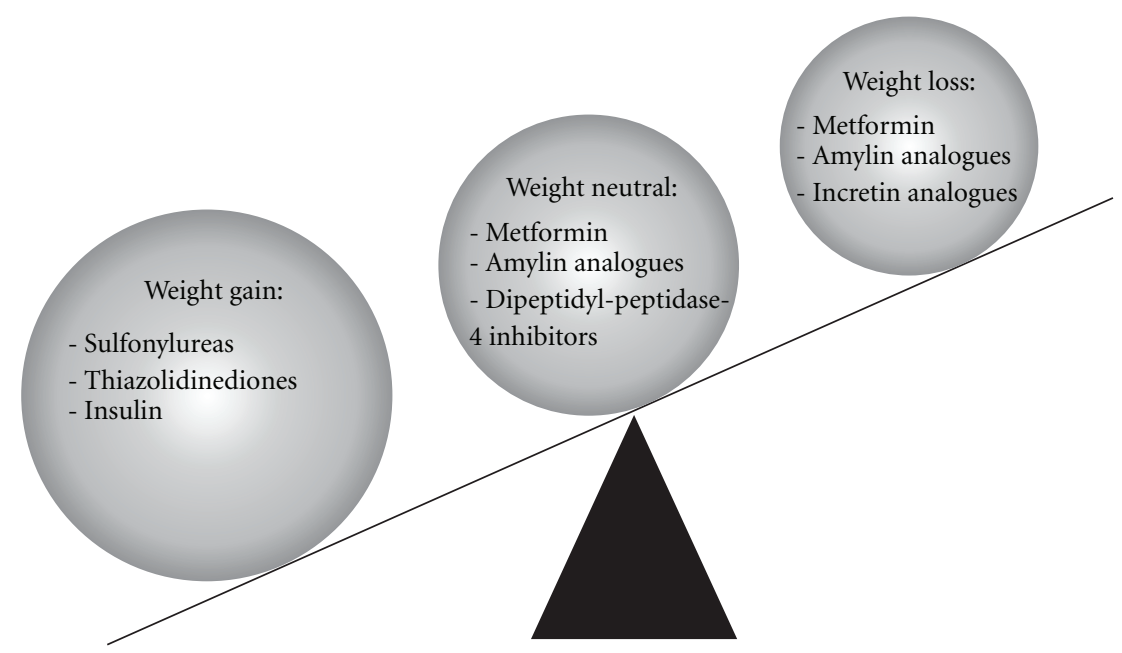

FIGURE 1: Effects of various antidiabetes agents on body weight.

\section{Antidiabetes Agents Associated with Weight Gain}

2.1. Sulfonylureas. The sulfonylureas (SUs) have been extensively used in the treatment of type 2 diabetes and are associated with weight gain. SUs stimulate pancreatic betacells directly to secrete insulin independent of glucose concentrations. SUs, when used as monotherapy, are expected to decrease HbA1c by 1-2\% [10, 11]. In UKPDS, 3,867 newly diagnosed patients with type 2 diabetes were randomized to intensive treatment with sulfonylurea (chlorpropamide 100$500 \mathrm{mg}$ or glibenclamide $2.5-20 \mathrm{mg}$ ), insulin, or conventional dietary management [6]. The median HbA1c of $7.0 \%$ in the intensive group was significantly lower compared with the conventional treatment $(7.9 \%)$ over the 10 -year study period. However, patients on the intensive treatment group had greater weight gain (mean $2.9 \mathrm{~kg} ; P<.001$ ) than the conventional group. Patients on glibenclamide gained $1.7 \mathrm{~kg}$ more than the conventional group whereas those on insulin gained $4.0 \mathrm{~kg}$ more.

To determine the effects of SU when combined with metformin, Garber et al. conducted a multicenter, doubleblind study in which 486 type 2 diabetes patients (mean $\mathrm{HbA} 1 \mathrm{c} \sim 8.7 \%$ ) were randomized to glyburide/metformin therapy $(1.25 / 250 \mathrm{mg})$, glyburide $(2.5 \mathrm{mg})$, or metformin (500 mg) monotherapy with titration to maximum doses for 16 weeks [12]. There was greater reduction in HbAlc $(-2.27 \%)$ in the glyburide/metformin group compared with both glyburide $(-1.90 \%)$ and metformin $(-1.53 \%)$ monotherapy $(P=.0003)$. Patients on glyburide/metformin treatment had a weight increase of $1.6 \mathrm{~kg}$ compared with $2.0 \mathrm{~kg}$ in the glyburide group $(P=\mathrm{NS})$. In contrast, patients on metformin had a weight loss of $1.1 \mathrm{~kg}$. Thus, the combination of SU with metformin results in superior glycemic control with less weight gain than SU monotherapy.

2.2. Thiazolidinediones. Thiazolidinediones (TZDs) reduce hyperglycemia primarily by improving insulin sensitivity in adipose, skeletal muscle, and liver tissues. These compounds may also have some favorable effects to preserve beta cell function and prevent diabetes development in patients at high risk $[13,14]$. TZDs are used as monotherapy or in combination with metformin or SUs in type 2 diabetes. In the Prospective Pioglitazone Clinical Trial in Macrovascular Events (PROactive) Study, 5,238 patients (mean HbAlc $\sim 7.8 \%$ ) were randomized to pioglitazone $15 \mathrm{mg}$ to $45 \mathrm{mg}$ $(n=2,605)$ or placebo $(n=2,633)$ in addition to their antidiabetes agents. Following the 34.5-month study period, the pioglitazone group achieved a reduction in HbAlc of $0.8 \%$ compared with $0.3 \%$ in the placebo group despite the addition of more antidiabetes agents in the placebo group [15]. There was an associated weight gain of $3.6 \mathrm{~kg}$ in the pioglitazone group as compared to a $0.4 \mathrm{~kg}$ weight loss in the placebo group. Despite weight gain, pioglitazone improved some secondary cardiovascular outcomes with regard to composite of all-cause mortality, nonfatal myocardial infarction, and stroke with multiple effects of lowering cholesterol and blood pressure.

The Diabetes Outcome Progression Trial (ADOPT) was done to evaluate rosiglitazone monotherapy on glycemic control compared with metformin or glyburide monotherapy. Patients (mean HbAlc $\sim 7.4 \%$ ) were randomized to receive maximum daily doses of rosiglitazone $8 \mathrm{mg}(n=$ $1,456)$, glyburide $15 \mathrm{mg}(n=1,441)$, or metformin $2 \mathrm{~g}(n=$ $1,454)$. At 4 years, $40 \%$ of patients in the rosiglitazone group had $\mathrm{HbA} 1 \mathrm{c}<7 \%$, as compared with $36 \%$ in the metformin group and $26 \%$ in the glyburide group [16]. Weight gain was a major consistent finding with the use of TZDs. Over a period of 5 years, treatment with rosiglitazone resulted in an average weight gain of $4.8 \mathrm{~kg}$ versus $1.6 \mathrm{~kg}$ in the glyburide group whereas patients on metformin had a decrease in weight $(-2.9 \mathrm{~kg})$. The weight gain associated with TZDs was postulated to be due to an increase in subcutaneous fat as a result of fat redistribution from visceral adipose tissues, which is related to major improvements in insulin sensitivity in hepatic and peripheral tissues [17]. 


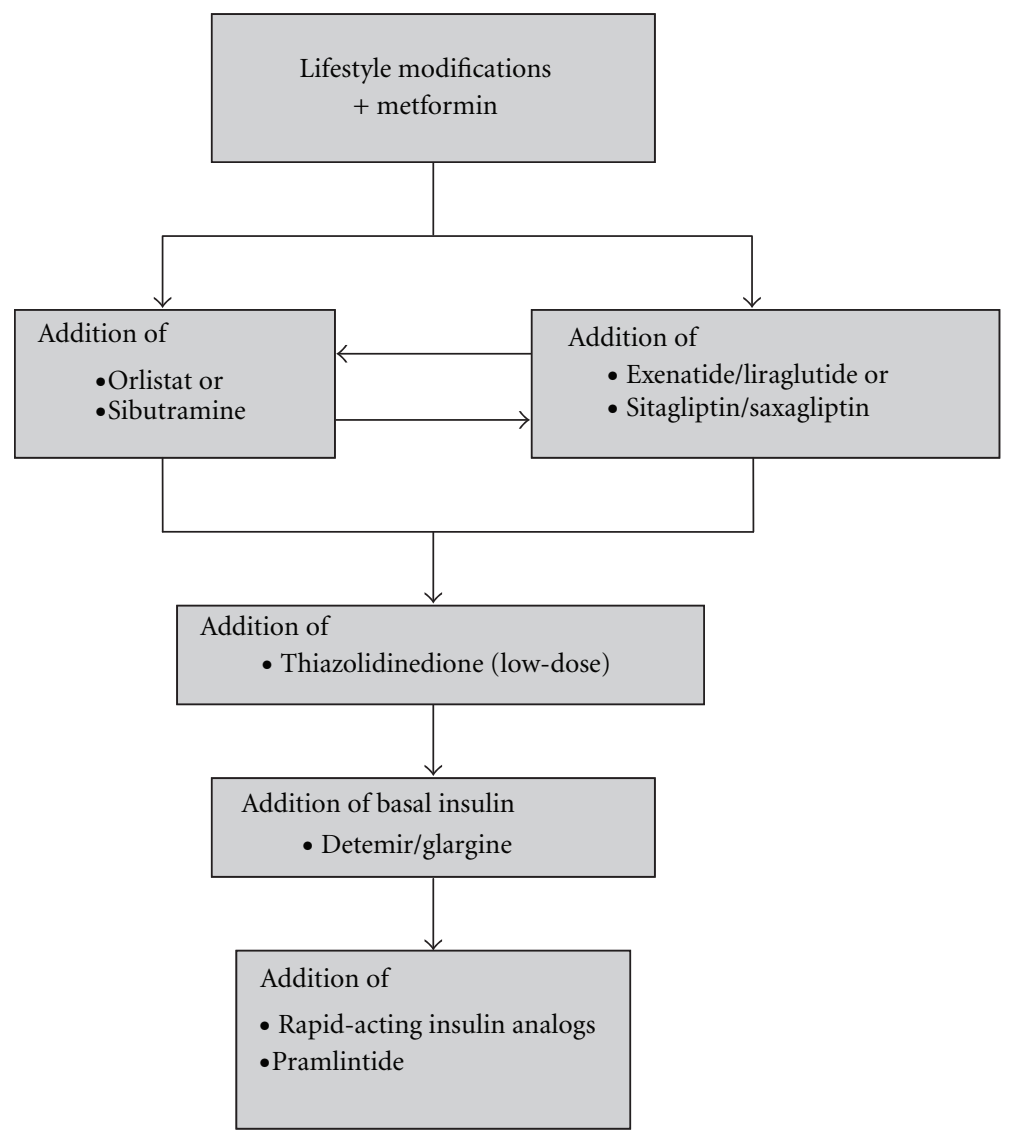

FIgURE 2: Practice-based approach for balancing weight loss and glycemic control (HbAlc $<7 \%)$ in uncomplicated type 2 diabetes.

The use of TZDs and metformin as an insulin-sensitizing strategy as compared to an insulin-providing strategy with SUs and insulin employed in diabetic patients with coronary artery disease enrolled in the BARI $2 \mathrm{D}$ trial had a greater likelihood of achieving glycemic control with HbAlc $<7 \%$ (insulin-sensitizing 55\% versus insulin-providing 40\%). Insulin-sensitizing therapy also was associated with less weight gain and hypoglycemia compared with the insulinproviding therapy [18].

The combination of TZDs with incretin agonists discussed below balances both glycemic and weight control. The addition of exenatide $10 \mu \mathrm{g}$ twice daily to rosiglitazone $4 \mathrm{mg}$ twice daily resulted in weight loss of $1.2 \mathrm{~kg}$ compared with weight gain of $1.5 \mathrm{~kg}$ with rosiglitazone monotherapy. There was also a greater reduction in $\mathrm{HbAlc}$ in the combination therapy group $(-1.3 \%$ versus $-1 \% ; P<.05)[19]$.

2.3. Insulin. By way of progressive loss of beta cell function, the majority of patients with diabetes will require insulin therapy to achieve glycemic control. Early initiation of multiple daily insulin injections allowed rapid achievement of glucose control and improvement in beta cell function [20]. This effect was sustained for up to two years after discontinuation of insulin [21]. Early intensive glucose control had been repeatedly shown to improve microvascular outcomes, however, at the expense of significant weight gain and hypoglycemia [6]. Weight gain from insulin use is related to its effect to increase body fat and lean mass through reductions in glycosuria, anabolic effects on adipose tissue, as well as to appetite-enhancing effects [22]. However, the type of basal insulin used may have different effects on weight. Rosenstock et al. compared the efficacy of insulin analogs detemir and glargine when added to oral glucoselowering agents in insulin-naïve type 2 diabetes subjects with baseline HbAlc of $8.6 \%$ in a 52 -week, open-label treat-totarget trial [23]. Treatment with insulin detemir $(n=291)$ and glargine $(n=291)$ resulted in a comparable decrease in HbAlc from 8.6 to 7.2 and $7.1 \%$, respectively. However, there were modest reductions in weight gain seen with determir versus glargine $(+3.0 \mathrm{~kg}$ versus $+3.9 \mathrm{~kg}, P=.01)$. Holman et al. conducted an open-label multicenter trial to evaluate the efficacy of basal insulin, prandial insulin, and biphasic insulin in type 2 diabetes patients inadequately controlled (mean $\mathrm{HbA1} \sim 8.5 \%$ ) on oral hypoglycemic agents [24]. Patients randomized to prandial insulin $(n=239)$ had a greater weight gain of $6.4 \pm 0.5 \mathrm{~kg}$ compared with patients on biphasic insulin $(n=235)$ with weight gain of $5.7 \pm 0.5 \mathrm{~kg}$ and basal insulin $(n=234)$ of $3.6 \pm 0.5 \mathrm{~kg}$. Clearly, the weight gain associated with insulin is a major drawback for treating diabetes. Further studies examining the effects of antiobesity drugs and GLP-1 agonists to combat insulin-induced weight gain are needed. 


\section{Antidiabetes Agents that Are Weight Neutral or Weight Reducing}

3.1. Metformin. Metformin is an insulin sensitizing agent that serves as the first line agent in treatment of type 2 diabetes and acts by decreasing hepatic glucose production and enhances peripheral tissue sensitivity to insulin. It has been shown to significantly delay the progression of impaired glucose tolerance to diabetes in the Diabetes Prevention Program (DPP) Study. This study was conducted to evaluate metformin in the prevention or delaying of the progression of type 2 diabetes in high-risk patients [5]. Patients who had impaired fasting glucose or impaired glucose tolerance test, were overweight and had a sedentary lifestyle were randomized to receive metformin $850 \mathrm{mg}$ twice daily ( $n=1,073$ ), lifestyle-modification (goal of $7 \%$ weight loss and 150 minutes of physical activity per week) program $(n=1,079)$, or placebo $(n=1,082)$ with a mean followup of 2.8 years. There was a $58 \%$ reduction in incidence of diabetes in the lifestyle-intervention group and 31\% reduction in the metformin group. Patients in the metformin group had a greater weight loss of $2.1 \mathrm{~kg}$ compared to placebo but less compared with the lifestyle-intervention group of $5.6 \mathrm{~kg}$.

Monotherapy with metformin reduced the HbA1c up to $1.5 \%$ [25]. DeFronzo et al. conducted a two-parallel-group, double-blind study to determine the efficacy of metformin in moderately obese patients with diabetes uncontrolled with diet or diet plus glyburide. In the first protocol $(n=$ 289 ), patients (mean HbAlc $\sim 8.3$ ) were randomized to metformin $(n=143)$ or placebo $(n=146)$ after an eightweek hypocaloric dietary phase. The addition of metformin resulted in the reduction of HbAlc by $1.4 \%$ versus $0.4 \%$ in the placebo group at 29 weeks. The metformin group experienced weight loss of $0.6 \mathrm{~kg}$ whereas the placebo group had a weight reduction of $1.1 \mathrm{~kg}(P=\mathrm{NS})$. In the second protocol $(n=632)$, the patients (mean HbA1c $~ 8.7 \%$ ) were started or continued on glyburide for five weeks. They were then randomized to glyburide $(n=209)$, metformin ( $n=210)$, and metformin-glyburide $(n=213)$. Patients given metformin-glyburide achieved a greater reduction in HbA1c of $1.7 \%$ compared with $0.4 \%$ with metformin alone. There was a weight loss of $3.8 \mathrm{~kg}$ in the metformin group compared with a weight gain of $0.4 \mathrm{~kg}$ in the metforminglyburide group.

In a double-blind, open-label study, metforminglibenclamide combination was compared with metforminrosiglitazone in 318 type 2 diabetes patients uncontrolled on metformin monotherapy (mean HbA1c 8.5\%) [26]. Patients randomized to metformin-glibenclamide $(n=160)$ had a greater reduction in Hbalc of $1.5 \%$ compared with metformin-rosiglitazone $(n=158)$ with a reduction in Hbalc of $1.1 \%$ at 24 weeks. There was a greater weight gain with the metformin-glibenclamide group compared with the metformin-rosiglitazone group $(+3.0 \mathrm{~kg}$ versus $+1.4 \mathrm{~kg})$. There is a general consensus that metformin is the treatment of choice in obese type 2 diabetes patients as it has been shown to be either weight neutral or even result in modest weight loss. However, combination with SUs or TZDs may result in weight gain whereas the combination with GLP-1 analogs may enhance weight loss.

3.2. Amylin Analogs. Pramlintide is an injectable synthetic analog of amylin which is a naturally occurring neuroendocrine hormone co-secreted with insulin by pancreatic beta cells in response to food intake. Pramlintide slows gastric emptying [27], attenuates postprandial glucagon secretion [28], enhances satiety, and reduces food intake [29]. In a 52-week, double-blind, multicenter trial, 656 patients (mean HbA1c 9.1\%) were randomized to subcutaneous injections of either placebo or pramlintide $(60 \mu \mathrm{g}$ TID, $90 \mu \mathrm{g}$ BID, or $120 \mu \mathrm{g}$ BID) in addition to their existing insulin regimen (alone or in combination with sulfonylureas and/or metformin) [30]. Treatment with pramlintide $120 \mu \mathrm{g}$ BID produced a significant reduction in $\mathrm{HbA} 1 \mathrm{c}$ of $0.68 \%$ at week 26 which was sustained at week 52 . This effect was accompanied by a mean weight loss of $1.4 \mathrm{~kg}$ compared with a weight gain of $0.7 \mathrm{~kg}$ in the placebo group $(P<.05)$. The addition of mealtime pramlintide $120 \mu \mathrm{g}(n=57)$ was compared with rapid-acting insulin analogs $(n=56)$ in addition to basal insulin in patients with inadequately controlled type $2 \mathrm{DM}$ ( $n=113$; mean HbA1c $~ 8.2 \%)$ in a 24 -week, randomized, open-label parallel-group, multicenter study [31]. Mealtime pramlintide and rapid-acting insulin analog (RAIA) resulted in a reduction of Hbalc of $1.1 \%$ versus $1.3 \%(P=.46)$, respectively. Pramlintide was weight neutral whereas RAIA use was associated with a weight gain of $4.7 \pm 0.7 \mathrm{~kg}$.

The efficacy of pramlintide was evaluated in obese, nondiabetic subjects in a double-blind, placebo-controlled doseranging study [32]. Four hundred and eleven obese subjects (BMI $~ 37.5)$ were randomized to receive pramlintide (120, 240 , and $360 \mu \mathrm{g}$ BID and TID) or placebo. Pramlintide at doses of $120 \mu \mathrm{g}$ TID and $360 \mu \mathrm{g}$ BID achieved weight loss of $3.2 \pm 1.2$ and $3.3 \pm 1.1 \mathrm{~kg}$, respectively, at 4 months. After completion of the 4-month study, 260 subjects continued to participate in the single-blind extension for 8 months. There was a progressive reduction in weight of $6.1 \pm 2.1$ and $7.2 \pm$ $2.3 \mathrm{~kg}$, respectively, at 12 months. In addition, 40 and $43 \%$ of patients treated with pramlintide $120 \mu \mathrm{g}$ BID and $360 \mu \mathrm{g}$ TID compared with $12 \%$ of patients in the placebo group achieved a reduction of $>10 \%$ of baseline weight. These data are encouraging in that weight control is possible with the use of amylin analogs in patients inadequately controlled on insulin therapy.

3.3. Glucagon-Like Peptide-1 (GLP-1) Analogs. GLP-1 analogs (exenatide and ligraglutide) are the latest medications used to treat diabetes and have favorable effects on both glycemic and weight control. In diabetes and obesity, the GLP-1 response to an oral glucose load is blunted contributing toward impaired insulin secretion and prandial hyperglycemia [33]. GLP-1 enhances insulin secretion in a glucose-dependent manner, accounting for about 50-70\% of the insulin secreted in response to oral glucose [34], and suppresses glucagon secretion [35]. Weight loss from GLP1 analogs results from the effects of hormone to promote satiety and slow gastric emptying $[36,37]$. Further, animal studies have shown beneficial effect of GLP-1 hormone on 
beta cell proliferation and inhibiting apoptosis [38]. These effects are of particular significance given that beta-cell failure occurs prior to the onset of diabetes.

Exenatide has a 53\% homology to human GLP-1. It is available subcutaneously and due to a short half-life of 2-4 hours, it is administered twice daily and at least 60 minutes before meals. In a 30-week triple-blind, placebocontrolled trial, 336 patients inadequately controlled on maximum doses of metformin (mean HbAlc $~ 8.2 \%$ ) were randomized to receive $5 \mu \mathrm{g}$ exenatide or placebo twice daily for 4 weeks followed by 5 or $10 \mu \mathrm{g}$ exenatide or placebo twice daily for 26 weeks [39]. Exenatide $5 \mu \mathrm{g}$ and $10 \mu \mathrm{g}$ resulted in a significant reduction in HbA1c $(-0.40 \%$ and $-0.78 \%$, resp.) compared with placebo $(+0.085 \%)$. Moreover, there was a dose-dependent reduction in body weight. Patients on exenatide $10 \mu \mathrm{g}$ had a weight loss of $2.8 \mathrm{~kg}$ compared with $1.6 \mathrm{~kg}$ on exenatide $5 \mu \mathrm{g}$. In an uncontrolled open-label extension of the prior 30-week study, 150 patients opted to continue exenatide treatment for another 52 weeks for a total of 82 weeks [40]. Exenatide was associated with a reduction in $\mathrm{HbAlc}$ of $1.0 \pm 0.1 \%$ and with weight loss of $3.0 \pm 0.6 \mathrm{~kg}$ at 30 weeks, effects were sustained at the end of 82 weeks with a final $\mathrm{HbAlc}$ reduction of $1.3 \pm 0.1 \%$ and weight loss of 5.3 $\pm 0.8 \mathrm{~kg}$.

The long-term efficacy of exenatide was assessed in an open-ended, open-label clinical trial in which patients from three placebo-controlled trials and their open-label extensions were enrolled for 3 years. A total of 217 patients completed the study [41]. The reduction in $\mathrm{HbAlc}$ from baseline to week $12(-1.1 \pm 0.1 \%)$ was sustained up to 3 years $(-1.0 \pm 0.1 \%)$. There was progressive reduction in body weight from baseline $(-5.3 \pm 0.4 \mathrm{~kg}$ at 3 years from $-1.6 \pm 0.2 \mathrm{~kg}$ at week 12). In addition to weight reduction, there was also a reduction in total body fat mass and truncal fat mass compared to the use of glargine [42]. The use of exenatide ( $10 \mu \mathrm{g}$ BID with a 4-week $5 \mu \mathrm{g}$ dose initiation) in addition to decreased calorie intake in nondiabetic obese subjects $(n=152)$ resulted in weight loss of $5.1 \pm 0.5 \mathrm{~kg}$ from baseline versus $1.6 \pm 0.5 \mathrm{~kg}$ with placebo at the end of a 24 week randomized study [43].

Liraglutide is more recently approved by FDA (January 2010) to be used as a once-daily subcutaneous injection for type 2 diabetes. In contrast to exenatide, liraglutide has a $97 \%$ homology to native human GLP-1 and has a longer half-life of 13 hours due to the presence of a fatty moiety allowing it to bind to albumin rendering it resistant to degradation by the DPP-4 enzyme [44]. Garber et al. conducted a 52-week double-blind, double-dummy, activecontrol, parallel-group study wherein 746 patients with early type 2 diabetes (mean $\mathrm{HbAlc} 8.2 \%$ ) were randomized to once-daily subcutaneous liraglutide $(1.2 \mathrm{mg}$ or $1.8 \mathrm{mg})$ or oral glimepiride $8 \mathrm{mg}$ [45]. Liraglutides $1.2 \mathrm{mg}$ and $1.8 \mathrm{mg}$ were associated with a reduction in HbAlc of $0.84 \%$ and $1.14 \%$, respectively, compared with $0.51 \%$ with glimepiride. There was a dose-dependent reduction in body weight with 1.2 and $1.8 \mathrm{mg}$ liraglutides $(-1.85 \mathrm{~kg}$ and $-2.26 \mathrm{~kg}$, resp.).

The addition of liraglutide with metformin and TZDs was studied in a 26-week, double-blind, placebo-controlled trial. Subjects $(n=533)$ were randomized to once-daily liraglutide $(1.2 \mathrm{mg}$ or $1.8 \mathrm{mg}$ ) or placebo in addition to metformin (1 g BID) and rosiglitazone (4 mg BID) [46]. The addition of liraglutide resulted in a mean reduction of $\mathrm{HbAlc}$ of $1.5 \%$ for both the 1.2 and $1.8 \mathrm{mg}$ liraglutide doses with a dose-dependent weight loss of $1-2 \mathrm{~kg}$. In a 26-week, multinational, parallel-group trial, liraglutide was compared to glargine in addition to metformin and sulfonylurea [47]. Five-hundred-eighty-one patients were randomized (2:1:2) to liraglutide $1.8 \mathrm{mg}(n=232)$, placebo $(n=115)$, and open-label insulin glargine $(n=234)$ in addition to metformin ( $1 \mathrm{~g}$ BID) and glimepiride $(4 \mathrm{mg}$ once daily). There was a greater reduction in $\mathrm{HbAlc}$ with liraglutide compared with insulin glargine $(-1.33 \%$ versus $-1.09 \%$ ). Liraglutide $1.8 \mathrm{mg}$ resulted in a mean weight loss of $1.8 \mathrm{~kg}$ from baseline compared with $0.42 \mathrm{~kg}$ in the placebo group. Patients on insulin glargine gained $1.6 \mathrm{~kg}$. In addition, waist circumference decreased significantly in the liraglutide group $(-1.50 \mathrm{~cm})$ whereas patients on insulin glargine had an increase in waist circumference $(+0.89 \mathrm{~cm})$.

Buse et al. compared the efficacy of liraglutide $1.8 \mathrm{mg}$ once daily with exenatide $10 \mu \mathrm{g}$ twice daily in a 26-week open-label, parallel-group multinational study [48]. Patients $(n=464)$ randomized to liraglutide $(n=233)$ had a greater reduction in $\mathrm{HbAlc}$ than to exenatide $(-1.12 \%$ versus $-0.79 \%$, resp.) and more patients achieved HbAlc value of $<7 \%$ with the liraglutide group ( $54 \%$ versus $43 \%$ ). Both groups achieved weight loss $(-3.24 \mathrm{~kg}$ versus $-2.87 \mathrm{~kg}$; $P=\mathrm{NS})$. The efficacy of liraglutide ( $1.2 \mathrm{mg}, 1.8 \mathrm{mg}, 2.4 \mathrm{mg}$, or $3.0 \mathrm{mg}$ ) was assessed in obese nondiabetic individuals in a 20-week double-blind, placebo-controlled trial with an open-label orlistat comparator [49]. Individuals in the liraglutide group significantly lost more weight compared to placebo at all doses $(P<.003)$ and orlistat group $(P=.003$ for liraglutide $2.4 \mathrm{mg}$ and $P<.001$ for liraglutide $3 \mathrm{mg}$ ). Mean weight loss with liraglutide at different doses ranged from an average of $4.8-7.2 \mathrm{~kg}$ compared with $2.8 \mathrm{~kg}$ with placebo and $4.1 \mathrm{~kg}$ with orlistat. About $76 \%$ of individuals $(n=70)$ on liraglutide $3.0 \mathrm{mg}$ lost $>5 \%$ of their weight compared with $30 \%(n=29)$ with placebo or $44 \%(n=$ 42) with orlistat. Liraglutide decreased the prevalence of prediabetes (impaired fasting glucose or impaired glucose tolerance) by $84-96 \%$ with 1.8 to $3 \mathrm{mg}$ per day.

3.4. Dipeptidyl-Peptidase- (DPP-) 4 Inhibitors. Sitagliptin, saxagliptin, and vildagliptin are DPP-4 inhibitors that inhibit the degradation of endogenous GLP-1. These are available as oral agents. Sitagliptin and saxagliptin are FDA approved for monotherapy and use with metformin for type 2 diabetes. Vildagliptin is approved for use in Europe. Aschner et al. evaluated the efficacy of sitagliptin as monotherapy in type 2 diabetes patients in a double-blind, placebo-controlled study [50]. A total of 741 patients with baseline HbA1c $8.0 \%$ were randomized to sitagliptin $100 \mathrm{mg}$ or $200 \mathrm{mg}$ once daily or placebo for 24 weeks. Sitagliptin at doses of 100 or $200 \mathrm{mg}$ had a significant reduction in HbAlc of 0.69 and $0.94 \%$, respectively, with no significant change in body weight.

In another double-blind, placebo-controlled, parallelgroup study in which 1091 patients with type 2 diabetes (mean HbAlc 8.8\%) were randomized to sitaglipin 
$100 \mathrm{mg} / \mathrm{metformin} 1000 \mathrm{mg}$ (S100/M1000 group), sitagliptin $100 \mathrm{mg} / \mathrm{metformin} 2000 \mathrm{mg}$ (S100/M2000 group), metformin $1000 \mathrm{mg}$ (M1000 group), metformin $2000 \mathrm{mg}$ (M2000 group), sitagliptin $100 \mathrm{mg}$ (S100 group), or placebo [51]. All treatment groups achieved a statistically significant reduction in $\mathrm{HbA1c}$ from baseline compared with placebo and respective monotherapies at 24 weeks $(P<.001)$. Patients in the S100/M2000 group had a reduction in Hba1c of $2.07 \%$, S100/M1000 group with a reduction of $1.57 \%$, M2000 group with a reduction of $1.30 \%$, M1000 group with a reduction of $0.99 \%$, and $\mathrm{S} 100$ group with reduction of $0.83 \%$. There were significant reductions in body weight from baseline $(-0.6$ to $1.3 \mathrm{~kg})$ in all groups, except in the sitagliptin group with no change in weight. Thus, as opposed to using SUs with metformin that may promote weight gain and run the risk of hypoglycemia, the use of DPP-4 inhibitors with metformin would be expected to result in less weight gain without the risk of hypoglycemia.

Similar to the effects of sitagliptin, saxagliptin at doses of $2.4,5$, and $10 \mathrm{mg}$, in addition to metformin, also similarly produced a significant reduction in HbAlc from baseline $(-0.59$ to $0.69 \%)$ with no significant change in weight [52].

\section{Use of Antiobesity Agents in Type 2 DM}

At present, there are only two antiobesity agents approved for long-term use by the FDA. These agents may be used with lifestyle modification and metformin. Orlistat and sibutramine have been studied in type 2 diabetes populations which will be briefly reviewed here.

4.1. Orlistat (Xenical). Orlistat is a lipase inhibitor that inhibits the absorption of dietary fat in the gastrointestinal tract by approximately $30 \%$ at dosage of $120 \mathrm{mg}$ three times daily in combination with a mildly hypocaloric diet [53]. Xenical in the Prevention of Diabetes in Obese Subjects (XENDOS) Study, a 4-year double-blind, prospective study, was conducted to determine the long-term effect of orlistat in reducing progression to type 2 diabetes [54]. Obese patients $\left(n=3,305 ; \mathrm{BMI} \sim 37 \mathrm{~kg} / \mathrm{m}^{2}\right)$ with normal $(79 \%)$ or impaired (21\%) glucose tolerance were randomized to lifestyle changes plus either orlistat $120 \mathrm{mg}$ or placebo, three times daily. Patients treated with orlistat achieved significantly greater weight loss $(5.8 \mathrm{~kg}$ ) compared to placebo $(3.0 \mathrm{~kg})$. More patients in the orlistat group achieved a weight loss of $\geq 10 \%$ compared to the placebo group (26\% versus $15.6 \%$ ). There was also a greater reduction in incidence of type 2 diabetes with the orlistat group versus the control group of $6.2 \%$ versus $9.0 \%$ corresponding to a risk reduction of $37.3 \%$.

Several studies were also conducted to determine the effect of orlistat in patients with type $2 \mathrm{DM}$. Jacob et al. conducted a multicenter double-blind, placebo-controlled study in which overweight or obese patients with type 2 diabetes (mean HbA1c $8.5 \%$; BMI $\sim 37 \mathrm{~kg} / \mathrm{m}^{2}$ ) on either metformin, sulfonylurea, and/or insulin were randomized to treatment with orlistat $120 \mathrm{mg}$ three times daily $(n=$ 1279) or placebo $(n=1271)$ [55]. Patients treated with orlistat had a statistically significant greater decrease in body weight $(-3.8 \mathrm{~kg})$ than placebo-treated patients $(-1.4 \mathrm{~kg})$ and a larger decrease in HbA1c compared with placebo $(-0.74 \%$ versus $-0.31 \%)$. In addition, patients with minimal weight loss ( $<1 \%$ of baseline body weight) were also found to have a significant improvement in glycemic control with orlistat (HbAlc $-0.29 \%)$ compared with placebo $( \pm 0.14 \%)$ suggesting that improvement of glycemic control associated with orlistat may be independent of weight loss. The greater reduction in weight loss and improvement in glycemic control with orlistat has also been shown consistently in combination with metformin and sulfonylureas [56, 57] or insulin [58] in individual studies. In a 52-week, randomized, double-blind placebo-controlled study in which type 2 diabetes patients $(n=220)$ treated with metformin alone or in combination with sulfonylurea were randomized to orlistat versus placebo [56]. Orlistat-treated patients achieved greater reduction in weight $(5 \%)$ versus placebo $(1.8 \%)$ as well as greater reduction in HbAlc $(-1.1 \%$ versus $-0.2 \%)$. These were also accompanied by greater improvements in beta cell function and insulin resistance. Thus, treatment with orlistat may counteract the weight gain effects associated with SUs and insulin and is currently available over the counter.

4.2. Sibutramine. Sibutramine is a serotonin-norepinephrine reuptake inhibitor. It acts by decreasing food intake by reducing appetite and increasing satiety [59]. In a multicenter, double-blind, placebo-controlled study, 348 obese patients (BMI $35 \mathrm{~kg} / \mathrm{m}^{2}$ ) were randomized to sibutramine $15 \mathrm{mg}$ daily or placebo [60]. The sibutramine-treated group had greater weight loss compared to placebo $(8.1 \mathrm{~kg}$ versus $5.1 \mathrm{~kg})$. More patients on the sibutramine group lost more than $5 \%$ (62\% versus $41 \%)$ and $10 \%$ (40\% versus $19 \%)$ of their baseline weight compared to placebo. Aronne et al. conducted a study to evaluate the effects of coadministration of pramlintide with sibutramine or phentermine in a 25 -week multicenter trial [61]. Overweight or obese, nondiabetic subjects $(n=244)$ were randomized to pramlintide $(120 \mu \mathrm{g}$ TID), pramlintide $(120 \mu \mathrm{g}$ TID) + oral sibutramine $(10 \mathrm{mg}$ once daily), or pramlintide $(120 \mu \mathrm{g}$ TID) + phentermine (37.5 mg once daily). Subjects who received combination treatment achieved greater weight loss $(-11.3 \mathrm{~kg})$ compared with pramlintide alone $(-3.6 \mathrm{~kg})$ or placebo $(-2.1 \mathrm{~kg})$.

McNulty et al. conducted a 12-month, prospective, double-blind study in which 195 subjects with type 2 diabetes (mean HbAlc 9.5\%; BMI 36 kg/m²) treated with metformin were randomized to sibutramine 15 or $20 \mathrm{mg}$ daily or placebo [62]. There was significant weight loss in the sibutramine group with both $15 \mathrm{mg}(-5.5 \pm 0.6 \mathrm{~kg})$ and $20 \mathrm{mg}(-8.0 \pm 0.9 \mathrm{~kg})$ doses compared to placebo $(-0.2 \pm$ $0.5 \mathrm{~kg}$ ) with no significant change in HbAlc. However, in subjects who lost more than $10 \%$ of their body weight, there was a significant decrease in HbAlc averaging 1.2\%. Gokcel et al. evaluated the efficacy of sibutramine in combination with oral hypoglycemic agents in obese patients with poorly controlled type 2 diabetes (mean HbA1c 9.9\%; BMI $38 \mathrm{~kg} / \mathrm{m}^{2}$ ) [63]. Sixty patients were randomized to sibutramine $10 \mathrm{mg}$ twice daily or placebo. Sibutramine induced a greater mean reduction in weight than placebo $(-9.61 \mathrm{~kg}$ versus $-0.91 \mathrm{~kg})$. HbAlc reduced significantly at 6 months 
by $2.73 \%$ in the sibutramine group compared with $0.53 \%$ in the placebo group. A recent randomized control trial of sibutramine compared with placebo on cardiovascular effects in obese patients has shown an increase in risk for myocardial infarction, however this increase wasn't noted in patients with diabetes [64]. Careful consideration for risk versus benefit is needed for the use of sibutramine for weight loss in diabetes.

4.3. Summary. In recent years, an increasing number of antidiabetes agents, which have varying effects on glycemic control and weight, have become available. The treatment of diabetes should not only focus on glycemic control as its sole intention, but it should factor in the effect of these various agents on weight as well, since obesity aggravates insulin resistance, beta cell failure, and cardiovascular risk. SUs, TZDs, and insulin, when used alone or in combination, are usually associated with modest weight gain, whereas metformin and amylin analogues are weight neutral or result in weight loss. DPP-4 inhibitors are weight neutral whereas GLP-1 analogues are associated with weight loss. Therefore, in contrast to the conventional glycemic control strategy that results in significant weight gain, we propose that aggressive weight loss with lifestyle modification and metformin remain the foremost strategy followed by the use of incretin analogs. If glycemic control remains inadequate, the addition of lowdose TZDs would be a reasonable approach followed by the addition of basal insulin as necessary. Alternatively, the use of antiobesity agents such as orlistat, phentermine, or sibutramine has been shown to prevent or delay the onset of type 2 diabetes in obese patients and minimize the weight gain associated with SUs and insulin. These strategies should help balance glycemic and weight control in patients with obesity and diabetes.

\section{Acknowledgment}

The authors are grateful to Dr. Charles Faiman for his thoughtful comments and editorial assistance with this paper.

\section{References}

[1] K. M. V. Narayan, J. P. Boyle, T. J. Thompson, E. W. Gregg, and D. F. Williamson, "Effect of BMI on lifetime risk for diabetes in the U.S," Diabetes Care, vol. 30, no. 6, pp. 1562-1566, 2007.

[2] Centers for Disease Control and Prevention (CDC), "Prevalence of overweight and obesity among adults with diagnosed diabetes-United States, 1988-1994 and 1999-2002," Morbidity and Mortality Weekly Report, vol. 53, no. 45, pp. 10661068, 2004.

[3] B. J. Goldstein, "Insulin resistance as the core defect in type 2 diabetes mellitus," American Journal of Cardiology, vol. 90, no. 5, pp. 3G-10G, 2002.

[4] R. A. DeFronzo, "Pathogenesis of type 2 diabetes mellitus," Medical Clinics of North America, vol. 88, no. 4, pp. 787-835, 2004.

[5] W. C. Knowler, E. Barrett-Connor, S. E. Fowler et al., "Reduction in the incidence of type 2 diabetes with lifestyle intervention or metformin," New England Journal of Medicine, vol. 346, no. 6, pp. 393-403, 2002.
[6] R. Turner, "Intensive blood-glucose control with sulphonylureas or insulin compared with conventional treatment and risk of complications in patients with type 2 diabetes (UKPDS 33)," Lancet, vol. 352, no. 9131, pp. 837-853, 1998.

[7] W. T. Friedewald, J. B. Buse, J. T. Bigger et al., "Effects of intensive glucose lowering in type 2 diabetes," New England Journal of Medicine, vol. 358, no. 24, pp. 2545-2559, 2008.

[8] S. Mäkimattila, K. Nikkilä, and H. Yki-Järvinen, "Causes of weight gain during insulin therapy with and without metformin in patients with Type II diabetes mellitus," Diabetologia, vol. 42, no. 4, pp. 406-412, 1999.

[9] D. M. Nathan, J. B. Buse, M. B. Davidson et al., "Medical management of hyperglycemia in type 2 diabetes: a consensus algorithm for the initiation and adjustment of therapy: a consensus statement of the american diabetes association and the european association for the study of diabetes," Clinical Diabetes, vol. 27, no. 1, pp. 4-16, 2009.

[10] J. Rosenstock, E. Samols, D. B. Muchmore, and J. Schneider, "Glimepiride, a new once-daily sulfonylurea: a double-blind placebo-controlled study of NIDDM patients," Diabetes Care, vol. 19, no. 11, pp. 1194-1199, 1996.

[11] D. C. Simonson, I. A. Kourides, M. Feinglos, H. Shamoon, and C. T. Fischette, "Efficacy, safety, and dose-response characteristics of glipizide gastrointestinal therapeutic system on glycemic control and insulin secretion in NIDDM. Results of two multicenter, randomized, placebo-controlled clinical trials," Diabetes Care, vol. 20, no. 4, pp. 597-606, 1997.

[12] A. J. Garber, D. S. Donovan Jr., P. Dandona, S. Bruce, and J.-S. Park, "Efficacy of glyburide/metformin tablets compared with initial monotherapy in type 2 diabetes," Journal of Clinical Endocrinology and Metabolism, vol. 88, no. 8, pp. 3598-3604, 2003.

[13] A. J. Hanley, B. Zinman, P. Sheridan, S. Yusuf, and H. C. Gerstein, "Effect of rosiglitazone and ramipril on $\beta$ cell function in people with impaired glucose tolerance or impaired fasting glucose," Diabetes Care, vol. 33, no. 3, pp. 608-613, 2010.

[14] A. H. Xiang, R. K. Peters, S. L. Kjos et al., "Effect of pioglitazone on pancreatic $\beta$-cell function and diabetes risk in Hispanic women with prior gestational diabetes," Diabetes, vol. 55, no. 2, pp. 517-522, 2006.

[15] J. A. Dormandy, B. Charbonnel, D. J. Eckland et al., "Secondary prevention of macrovascular events in patients with type 2 diabetes in the PROactive Study (PROspective pioglitAzone Clinical Trial in macroVascular Events): a randomised controlled trial," Lancet, vol. 366, no. 9493, pp. 1279-1289, 2005.

[16] S. E. Kahn, S. M. Haffner, M. A. Heise et al., "Glycemic durability of rosiglitazone, metformin, or glyburide monotherapy," New England Journal of Medicine, vol. 355, no. 23, pp. 24272443, 2006.

[17] Y. Miyazaki, A. Mahankali, M. Matsuda et al., "Effect of pioglitazone on abdominal fat distribution and insulin sensitivity in type 2 diabetic patients," Journal of Clinical Endocrinology and Metabolism, vol. 87, no. 6, pp. 2784-2791, 2002.

[18] R. L. Frye, P. August, M. M. Brooks et al., "A randomized trial of therapies for type 2 diabetes and coronary artery disease," New England Journal of Medicine, vol. 360, no. 24, pp. 25032515, 2009.

[19] R. A. DeFronzo, C. Triplitt, Y. Qu, M. S. Lewis, D. Maggs, and L. C. Glass, "Effects of exenatide plus rosiglitazone on beta-cell function and insulin sensitivity in subjects with type 2 diabetes on metformin," Diabetes care, vol. 33, no. 5, pp. 951-957, 2010. 
[20] J. Weng, Y. Li, W. Xu et al., "Effect of intensive insulin therapy on $\beta$-cell function and glycaemic control in patients with newly diagnosed type 2 diabetes: a multicentre randomised parallel-group trial," The Lancet, vol. 371, no. 9626, pp. 1753$1760,2008$.

[21] W. Xu, Y.-B. Li, W.-P. Deng, Y.-T. Hao, and J.-P. Weng, "Remission of hyperglycemia following intensive insulin therapy in newly diagnosed type 2 diabetic patients: a long-term followup study," Chinese Medical Journal, vol. 122, no. 21, pp. 25542559, 2009.

[22] A. Barnett, J. Allsworth, K. Jameson, and R. Mann, "A review of the effects of antihyperglycaemic agents on body weight: the potential of incretin targeted therapies," Current Medical Research and Opinion, vol. 23, no. 7, pp. 1493-1507, 2007.

[23] J. Rosenstock, M. Davies, P. D. Home, J. Larsen, C. Koenen, and G. Schernthaner, "A randomised, 52-week, treat-to-target trial comparing insulin detemir with insulin glargine when administered as add-on to glucose-lowering drugs in insulinnaive people with type 2 diabetes," Diabetologia, vol. 51, no. 3, pp. 408-416, 2008.

[24] R. R. Holman, K. I. Thorne, A. J. Farmer et al., "Addition of biphasic, prandial, or basal insulin to oral therapy in type 2 diabetes," New England Journal of Medicine, vol. 357, no. 17, pp. 1716-1730, 2007.

[25] R. A. DeFronzo and A. M. Goodman, "Efficacy of metformin in patients with non-insulin-dependent diabetes mellitus. the multicenter metformin study group," The New England Journal of Medicine, vol. 333, no. 9, pp. 541-549, 1995.

[26] A. Garber, E. Klein, S. Bruce, S. Sankoh, and P. Mohideen, "Metformin-glibenclamide versus metformin plus rosiglitazone in patients with type 2 diabetes inadequately controlled on metformin monotherapy," Diabetes, Obesity and Metabolism, vol. 8, no. 2, pp. 156-163, 2006.

[27] A. Vella, J. S. Lee, M. Camilleri et al., "Effects of pramlintide, an amylin analogue, on gastric emptying in type 1 and 2 diabetes mellitus," Neurogastroenterology and Motility, vol. 14, no. 2, pp. 123-131, 2002.

[28] M. Fineman, C. Weyer, D. G. Maggs, S. Strobel, and O. G. Kolterman, "The human amylin analog, pramlintide, reduces postprandial hyperglucagonemia in patients with type 2 diabetes mellitus," Hormone and Metabolic Research, vol. 34, no. 9, pp. 504-508, 2002.

[29] I. Chapman, B. Parker, S. Doran et al., "Effect of pramlintide on satiety and food intake in obese subjects and subjects with type 2 diabetes," Diabetologia, vol. 48, no. 5, pp. 838-848, 2005.

[30] P. A. Hollander, P. Levy, M. S. Fineman et al., "Pramlintide as an adjunct to insulin therapy improves long-term glycemic and weight control in patients with type 2 diabetes: a 1-year randomized controlled trial," Diabetes Care, vol. 26, no. 3, pp. 784-790, 2003.

[31] M. Riddle, R. Pencek, S. Charenkavanich, K. Lutz, K. Wilhelm, and L. Porter, "Randomized comparison of pramlintide or mealtime insulin added to basal insulin treatment for patients with type 2 diabetes," Diabetes Care, vol. 32, no. 9, pp. 15771582, 2009.

[32] S. R. Smith, L. J. Aronne, C. M. Burns, N. C. Kesty, A. E. Halseth, and C. Weyer, "Sustained weight loss following 12-month pramlintide treatment as an adjunct to lifestyle intervention in obesity," Diabetes Care, vol. 31, no. 9, pp. 1816$1823,2008$.

[33] T. Vilsbøll, T. Krarup, C. F. Deacon, S. Madsbad, and J. J. Holst, "Reduced postprandial concentrations of intact biologically active glucagon-like peptide 1 in type 2 diabetic patients," Diabetes, vol. 50, no. 3, pp. 609-613, 2001.

[34] M. A. Nauck, E. Homberger, and E. G. Siegel, "Incretin effects of increasing glucose loads in man calculated from venous insulin and C-peptide responses," Journal of Clinical Endocrinology and Metabolism, vol. 63, no. 2, pp. 492-498, 1986.

[35] D. J. Drucker, "Enhancing incretin action for the treatment of type 2 diabetes," Diabetes Care, vol. 26, no. 10, pp. 2929-2940, 2003.

[36] J. J. Meier, B. Gallwitz, S. Salmen et al., "Normalization of glucose concentrations and deceleration of gastric emptying after solid meals during intravenous glucagon-like peptide 1 in patients with type 2 diabetes," Journal of Clinical Endocrinology and Metabolism, vol. 88, no. 6, pp. 2719-2725, 2003.

[37] A. Flint, A. Raben, A. K. Ersbøll, J. J. Holst, and A. Astrup, "The effect of physiological levels of glucagon-like peptide-1 on appetite, gastric emptying, energy and substrate metabolism in obesity," International Journal of Obesity, vol. 25, no. 6, pp. 781-792, 2001.

[38] L. Farilla, H. Hongxiang, C. Bertolotto et al., "Glucagon-like peptide-1 promotes islet cell growth and inhibits apoptosis in zucker diabetic rats," Endocrinology, vol. 143, no. 11, pp. 43974408, 2002.

[39] R. A. DeFronzo, R. E. Ratner, J. Han, D. D. Kim, M. S. Fineman, and A. D. Baron, "Effects of exenatide (exendin-4) on glycemic control and weight over 30 weeks in metformintreated patients with type 2 diabetes," Diabetes Care, vol. 28, no. 5, pp. 1092-1100, 2005.

[40] R. E. Ratner, D. Maggs, L. L. Nielsen et al., "Long-term effects of exenatide therapy over 82 weeks on glycaemic control and weight in over-weight metformin-treated patients with type 2 diabetes mellitus," Diabetes, Obesity and Metabolism, vol. 8, no. 4, pp. 419-428, 2006.

[41] D. C. Klonoff, J. B. Buse, L. L. Nielsen et al., "Exenatide effects on diabetes, obesity, cardiovascular risk factors and hepatic biomarkers in patients with type 2 diabetes treated for at least 3 years," Current Medical Research and Opinion, vol. 24, no. 1, pp. 275-286, 2008.

[42] M. C. Bunck, M. Diamant, A. Cornér et al., "One-year treatment with exenatide improves $\beta$-cell function, compared with insulin glargine, in metformin-treated type 2 diabetic patients: a randomized, controlled trial," Diabetes Care, vol. 32, no. 5, pp. 762-768, 2009.

[43] J. Rosenstock, L. J. Klaff, S. Schwartz, J. Northrup, J. H. Holcombe, and K. Wilhelm, "Effects of exenatide and lifestyle modification on body weight and glucose tolerance in obese subjects with and without prediabetes," Diabetes Care, vol. 33, no. 6, pp. 1173-1175, 2010.

[44] J. Jendle, M. A. Nauck, D. R. Matthews et al., "Weight loss with liraglutide, a once-daily human glucagon-like peptide1 analogue for type 2 diabetes treatment as monotherapy or added to metformin, is primarily as a result of a reduction in fat tissue," Diabetes, Obesity and Metabolism, vol. 11, no. 12, pp. 1163-1172, 2009.

[45] A. Garber, R. Henry, R. Ratner et al., "Liraglutide versus glimepiride monotherapy for type 2 diabetes (LEAD3 Mono): a randomised, 52-week, phase III, double-blind, parallel-treatment trial," The Lancet, vol. 373, no. 9662, pp. 473-481, 2009.

[46] B. Zinman, J. Gerich, J. B. Buse et al., "Efficacy and safety of the human glucagon-like peptide-1 analog liraglutide in combination with metformin and thiazolidinedione in 
patients with type 2 diabetes (LEAD-4 Met+TZD)," Diabetes Care, vol. 32, no. 7, pp. 1224-1230, 2009.

[47] D. Russell-Jones, A. Vaag, O. Schmitz et al., "Liraglutide vs insulin glargine and placebo in combination with metformin and sulfonylurea therapy in type 2 diabetes mellitus (LEAD5 met+SU): a randomised controlled trial," Diabetologia, vol. 52, no. 10, pp. 2046-2055, 2009.

[48] J. B. Buse, J. Rosenstock, G. Sesti et al., "Liraglutide once a day versus exenatide twice a day for type 2 diabetes: a 26week randomised, parallel-group, multinational, open-label trial (LEAD-6)," The Lancet, vol. 374, no. 9683, pp. 39-47, 2009.

[49] A. Astrup, S. Rössner, L. Van Gaal et al., "Effects of liraglutide in the treatment of obesity: a randomised, double-blind, placebo-controlled study," The Lancet, vol. 374, no. 9701, pp. 1606-1616, 2009.

[50] P. Aschner, M. S. Kipnes, J. K. Lunceford, M. Sanchez, C. Mickel, and D. E. Williams-Herman, "Effect of the dipeptidyl peptidase-4 inhibitor sitagliptin as monotherapy on glycemic control in patients with type 2 diabetes," Diabetes Care, vol. 29, no. 12, pp. 2632-2637, 2006.

[51] B. J. Goldstein, M. N. Feinglos, J. K. Lunceford, J. Johnson, and W.-H. De, "Effect of initial combination therapy with sitagliptin, a dipeptidyl peptidase- 4 inhibitor, and metformin on glycemic control in patients with type 2 diabetes," Diabetes Care, vol. 31, no. 8, pp. 1979-1987, 2008.

[52] R. A. DeFronzo, M. N. Hissa, A. J. Garber et al., "The efficacy and safety of saxagliptin when added to metformin therapy in patients with inadequately controlled type 2 diabetes with metformin alone," Diabetes Care, vol. 32, no. 9, pp. 1649-1655, 2009.

[53] R. Guerciolini, "Mode of action of orlistat," International Journal of Obesity, vol. 21, supplement 3, pp. S12-S23, 1997.

[54] J. S. Torgerson, J. Hauptman, M. N. Boldrin, and L. Sjöström, "XENical in the prevention of diabetes in obese subjects (XENDOS) study: a randomized study of orlistat as an adjunct to lifestyle changes for the prevention of type 2 diabetes in obese patients," Diabetes Care, vol. 27, no. 1, pp. 155-161, 2004.

[55] S. Jacob, M. Rabbia, M. K. Meier, and J. Hauptman, "Orlistat $120 \mathrm{mg}$ improves glycaemic control in type 2 diabetic patients with or without concurrent weight loss," Diabetes, Obesity and Metabolism, vol. 11, no. 4, pp. 361-371, 2009.

[56] C. Berne, "A randomized study of orlistat in combination with a weight management programme in obese patients with Type 2 diabetes treated with metformin," Diabetic Medicine, vol. 22, no. 5, pp. 612-618, 2005.

[57] J. M. Miles, L. Leiter, P. Hollander et al., "Effect of orlistat in overweight and obese patients with type 2 diabetes treated with metformin," Diabetes Care, vol. 25, no. 7, pp. 1123-1128, 2002.

[58] D. E. Kelley, G. A. Bray, F. X. Pi-Sunyer et al., "Clinical efficacy of orlistat therapy in overweight and obese patients with insulin-treated type 2 diabetes: a 1-year randomized controlled trial," Diabetes Care, vol. 25, no. 6, pp. 1033-1041, 2002.

[59] B. Barkeling, K. Elfhag, P. Rooth, and S. Rössner, "Shortterm effects of sibutramine (Reductil) on appetite and eating behaviour and the long-term therapeutic outcome," International Journal of Obesity, vol. 27, no. 6, pp. 693-700, 2003.

[60] H. Hauner, M. Meier, G. Wendland, T. Kurscheid, and K. Lauterbach, "Weight reduction by sibutramine in obese subjects in primary care medicine: the S.A.T. study," Experimental and Clinical Endocrinology and Diabetes, vol. 112, no. 4, pp. 201-207, 2004.

[61] L. J. Aronne, A. E. Halseth, C. M. Burns, S. Miller, and L. Z. Shen, "Enhanced weight loss following coadministration of pramlintide with sibutramine or phentermine in a multicenter trial," Obesity, vol. 18, no. 9, pp. 1739-1746, 2010.

[62] S. J. McNulty, E. Ur, and G. Williams, "A randomized trial of sibutramine in the management of obese type 2 diabetic patients treated with metformin," Diabetes Care, vol. 26, no. 1, pp. 125-131, 2003.

[63] A. Gokcel, H. Karakose, E. M. Ertorer, N. Tanaci, N. B. Tutuncu, and N. Guvener, "Effects of sibutramine in obese female subjects with type 2 diabetes and poor blood glucose control," Diabetes Care, vol. 24, no. 11, pp. 1957-1960, 2001.

[64] W. Philip T. James, Ian D. Caterson, Walmir Coutinho et al., "Effect of Sibutramine on Cardiovascular Outcomes in Overweight and Obese Subjects," The New England Journal of Medicine, vol. 363, no. 10, pp. 905-917, 2010. 


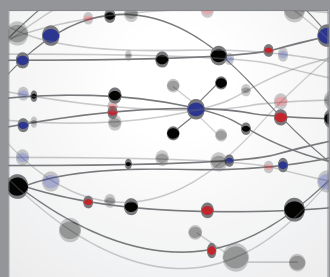

The Scientific World Journal
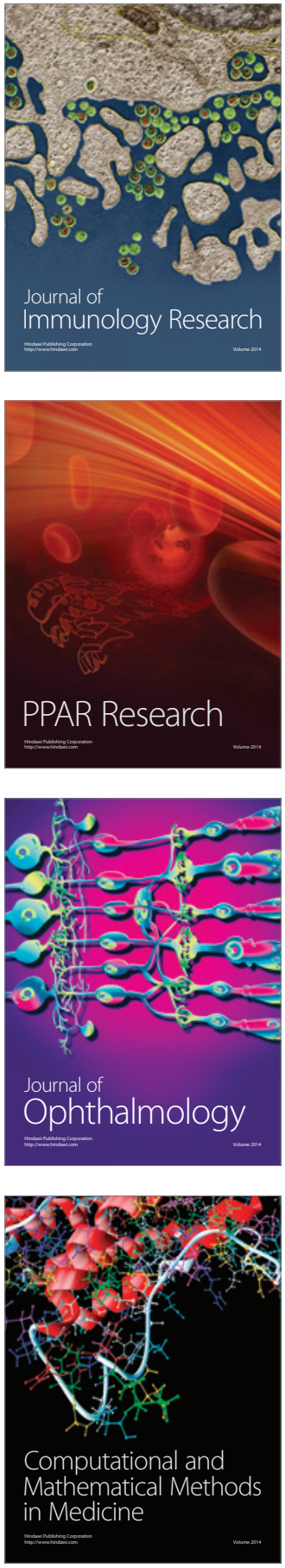

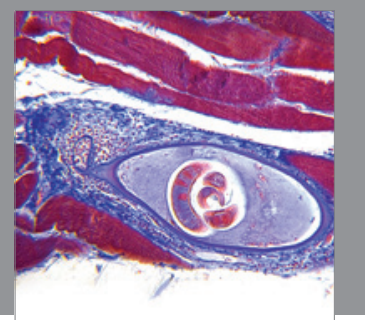

Gastroenterology

Research and Practice
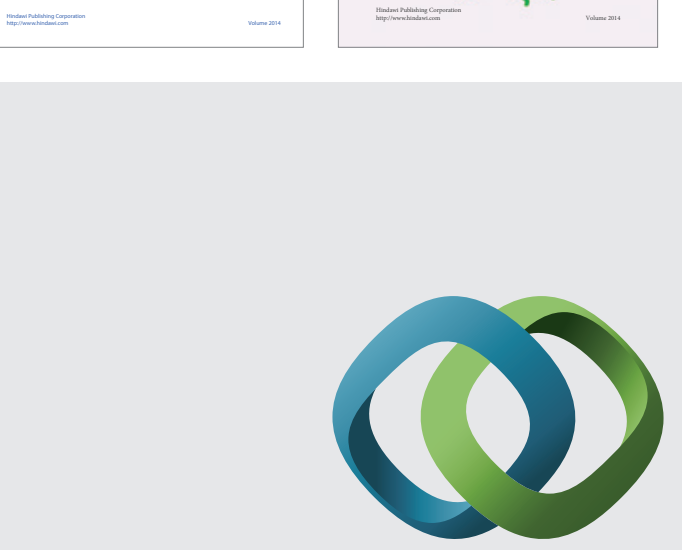

\section{Hindawi}

Submit your manuscripts at

http://www.hindawi.com
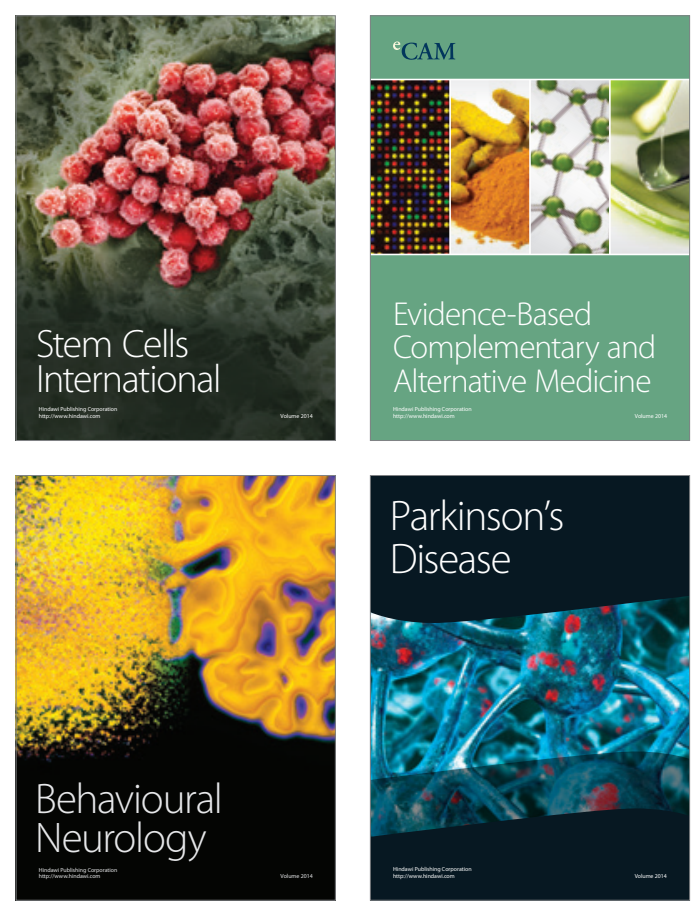

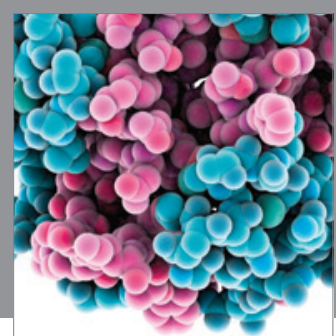

Journal of
Diabetes Research

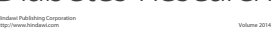

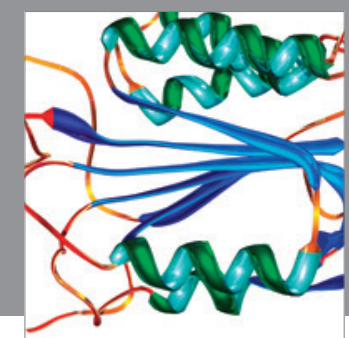

Disease Markers
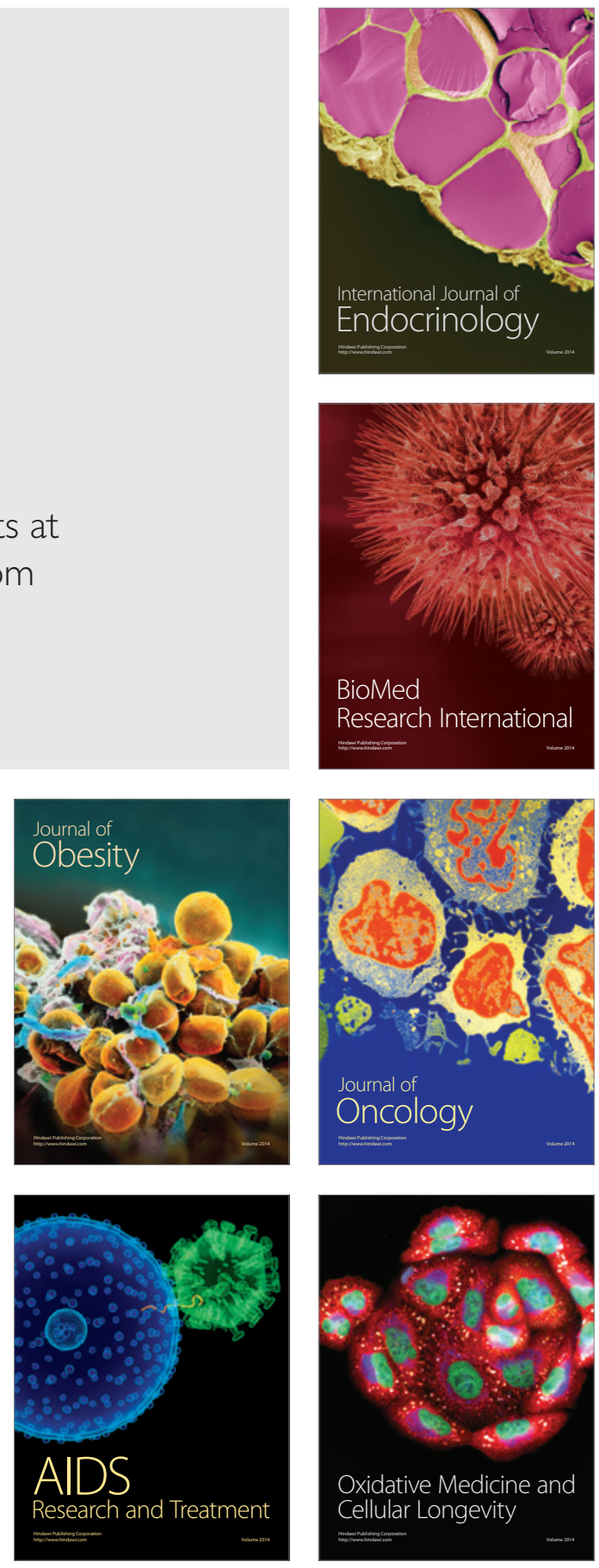